\title{
Interview with Mike Parker Pearson
}

\author{
Interview conducted by Thomas J. T. Williams and Hana Koriech, \\ 12th November 2011
}

\begin{abstract}
Mike Parker Pearson is the Institute of Archaeology's newly appointed Professor of British Later Prehistory. In this interview he reflects on his experience at the birth of post-processualism, current problems and opportunities in modern archaeology, and the subject for which he is best known: Stonehenge.
\end{abstract}

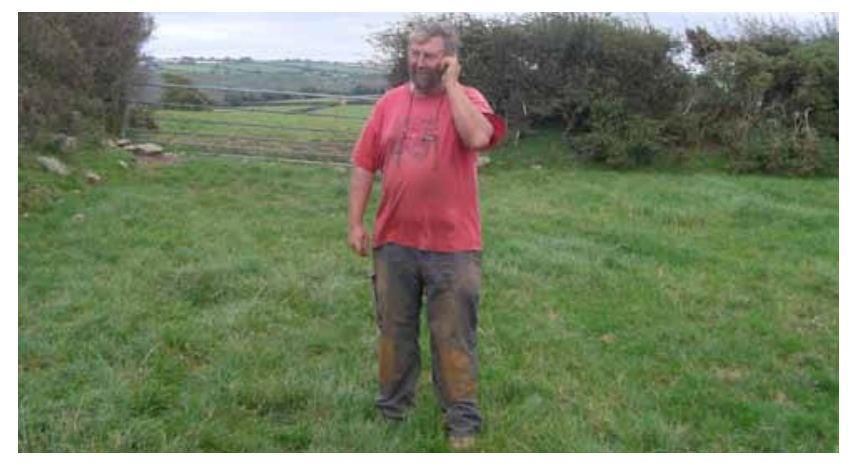

PIA: After 22 years at Sheffield University, what made you leave?

MPP: I wasn't going to leave at all, but Steve (Stephen Shennan, IoA Director) was very persistent!

\section{PIA: What are your first impressions?}

MPP: I'm loving it here! It's an area of London I've known for years because of course I used to work in London in the '80s anyway so in a way it's coming back to old haunts. I've got a lot of friends here who I've known for a very long time. So, for example, Todd Whitelaw and I were students together in Southampton back in the late '70s, and others I've known for decades - there is a whole contingent of ex-Sheffield folk here for example and of course many more that I've known one way or another.

\section{PIA: How did you first get involved in archaeology?}

MPP: It was certainly something I always knew I wanted to do, [at least] from the age of four, when I first started picking up fossils and wondering what they were. At that point my parents were living in Oxfordshire near the Uffington White Horse so I was always looking at the earthworks,,walking about up there ... after that, I took every opportunity that there was. Another of the key moments in my past was the very first time I went on an excavation - not just turning up for the day but camping and realising this was the best fun that could be had.

\section{PIA: What excavation was that?}

MPP: It was a small Roman site in Somerset called Catsgore run by someone called Roger Leech [now visiting Professor at the University of Southampton and former Head of Archaeology at the Royal Commission on the Historical Monuments of England]. That was 1973, so I've been digging for almost 40 years.

PIA: Do you see any barriers now for young people to participate in archaeology, compared to the situation in the 1970s?

MPP: I think it's very difficult these days because we are so professionalised that in 
commercial archaeology there is very little opportunity to actually go onto site - you've got health and safety, insurance issues and all the rest of it... I think one of the most important things is that there are still excavations that allow people to do that because that for many people is the gateway. But of course life doesn't make it easy; it's very hard to go if you're under 16 - you're into the world of CRB checks and unnecessary bureaucratisation. So I think it's difficult. For those that are coming out of university to get jobs in commercial archaeology you're not in an environment that's always much fun - you may be digging a big site, but there's more likely to be five of you than fifty and you're really just staying in a series of $\mathrm{B} \& \mathrm{Bs}$ rather than it all being an adventure and an experience with a capital ' $E$ '. One of the things I've tried to do in recent years is to make it possible for students and professionals - who have been coming on busman's holidays to our Stonehenge project - that it is a fun experience as well as about getting the work done.

\section{PIA: How do you feel about the changes brought about by the commercialisation of archaeology?}

MPP: We were embarking on a new profession back then. The State basically funded archaeology and the volunteering payments - which were $£ 7.50$ a week - were easily enough to live on back then because you were either camping or living in no rent accommodation. We forget that all we've seen with commercialisation is that responsibility has shifted from the public sector to the private sector and with that has come all of the paraphernalia of codes of practise and all that. And I suppose when I was working in public archaeology after I did my PhD that was the moment of transition. It was already in progress because by 1984 you already had the three big units - Oxford, Wessex and MoLAS here in London -taking money from developers and saying if you pay us this we'll help you get your plan- ning permission, this will help you get your development faster than if you're obstructive'. So by the time we got the planning policy guidance out in 1990 it was really just a case of dotting 'i's and crossing 't's, but it did mean that there was then a uniform system of how to do development archaeology and it put the emphasis on the developer as the 'polluter who pays'. So I think that's what we saw. And I think the other business was that as central government was pulling out - and this happened right through the Thatcher decade - so local and regional units were forced to diversify. They would get their funding from local government, set themselves up as charities...[they found] lots of different fundraising avenues because they realised they could rely on central government less and less and less. It was interesting when that was all happening and to see the biggest sea change we've had. I don't think it necessarily means we do better archaeology... we certainly do a lot more of it because it did give us the facility to do evaluations in advance of planning permissions which wasn't there before, but I think it's meant that some of the set-piece mitigation - large open-area excavation - is done with slightly more corner-cutting than we would have liked to have seen back in the' good old days' of the 1970s. But then terrible things happened then too - entire city centres got wiped out with very little investigation.

\section{PIA: What do you think is the role of aca- demia in modern archaeology?}

MPP: I think it's very true that we don't play a wide enough role in the public promulgation of what we do and it's something that was noted almost a decade ago when Current Archaeology pointed out that a lot of their news stories were coming from the growing commercial sector as opposed to the academic sector. I think we've seen a sea change in that respect. Of course it's always going to change because now there aren't a lot of stories coming out of the commercial sector 
except how many people have been losing their jobs; there isn't the mass of big projects going on out there that there used to be. It's something that's constantly being redefined. What's happening with the government making everybody pay for themselves is that the actual value of what you do as research in the humanities is going to fall; effectively it says that your only value is to teach students to try to become high wage earners. So it's not a great time to be in universities by any means and probably not a great time to be looking for jobs in the public sector in archaeology.

PIA: You were part of the development of post-processual archaeology when you were supervised by Ian Hodder at Cambridge. What was the academic environment like at that time? Were you aware of the massive changes it would bring?

MPP: Oh yes. I think that we knew we were completely recasting the relationship between human behaviour and material culture and I was very impressed with Hodder because he was unwavering in the face of enormous opposition. He was shouted down at conferences, he was heckled at any opportunity and a lot of the supposedly academic dialogue was extremely nasty. And I thought if that had been me I could not have actually stood up to it; he was only 32 at the time - a very young man. But I think I realised that he was probably on to something because all the other humanities had already changed tack and we were merely catching up, as usual 5-10 years behind everybody else. So it was a very exciting time to be a post-grad: right in the heart of the whirlwind, in the eye of the hurricane. It was also a difficult time, because a lot of the arguments were quite heated and antagonistic, so we regularly had slanging matches with New Archaeologists like Lewis Binford who believed that for an academic to change their mind was a sign of weakness - that was supposed to be reserved for politics.

\section{PIA: Do you think archaeology is lacking something without those certainties and ideological battles?}

MPP: No. Not at all. I just feel so pleased that we've moved beyond all of that because whilst it was great stuff for intellectual zealotry, tub-thumping about whose side was right and building the egos of a number of silver-back males in particular - I think that what we have now is a million times better. It's not a matter of ideological preference - whether you're a post-modernist or an empiricist-positivist... the thing is that we live in a much more eclectic world where we simply choose what's appropriate; we choose the best theories and models and we work not to imprint onto the data but to try to get the data to tell us something about the past. I think we've come through that growingup phase - which was very important and it was essential that we did it - and we can actually get back to the pursuit of the past: actually working as archaeologists to find things out and to communicate them. So no, I don't miss it for a moment. Perhaps it's a shame for some PhD students who would have loved to have had that kind of cut and thrust as part of their growing up, and at that stage I think probably everybody needs to find someone to follow - a guru - but in a way the most important thing to learn is that you don't need to follow anybody else; what you're doing is learning to follow your own nose, and it's very hard at that stage in life because people want to have someone whose work they adore and who cannot be criticised: whether it's a French philosopher or an American cultural ecologist.

\section{PIA: Was it scary?}

MPP: Utterly terrifying, yes.

\section{PIA: Was there a distinct group of you working under Ian?}

MPP: We were the 'coggies', the 'cognitive archaeologists', before the term 'post-processualist' was coined. Chris Tilley and Danny Miller 
were a year above me and they're both over there [in the UCL anthropology department], Henrietta Moore [Professor of Social Anthropology at the University of Cambridge] was the same year as me, Sheena Crawford, Alice Welbourne ... Ellen Pader [Associate Professor of Regional Planning, University of Massachusetts, Amherst] was a couple of years further along. I guess we probably were about ten or a dozen - a dozen is a good number for a bunch of acolytes - and I think the interesting aspect about it was that it was a very well organised research programme because lan gave each of us a particular material topic. So I got 'death and burial', 'rubbish' went to Henrietta, Chris was doing design and motifs on ceramics. So everybody was given a particular angle, and the main thrust of it was ethnoarchaeology and really embracing cultural anthropology - basically catching up on what they had been doing in that discipline for the last decade and a half, and then working out how some of those ideas could be applied. Ian has always striven to recreate that but he's never been able to do it - he just happened to be in the right place at the right time. And it hasn't happened anywhere else, except of course for the previous paradigm - the New Archaeology - which was very much an American thing.

\section{PIA: What is the current focus of your research?}

MPP: Well, basically, it's Stonehenge. We're writing up three large research monographs: the work of this last decade. We started properly in 2003 and we've been through an evolution of different projects. It started with the 'Stonehenge Riverside Project' and then at the same time we also started looking at the isotopes for diet and mobility in the Beaker burials from the second half of the third millennium B.C. Then the 'Stonehenge Riverside Project' morphed into 'Feeding Stonehenge' as we moved into the post-excavation phase. We said 'ok, let's do isotopes on the animals and find out where they're all coming from'; and we're just finding out that they're coming from all the geological regions of the
United Kingdom including Highland Scotland, which is quite extraordinary. That has then morphed into a new project called the 'Stones of Stonehenge' where we're looking at where the quarries are for Stonehenge. We've known for a long time that they're in Wales and North Wiltshire but we've never actually 'found' them. So it's splitting into two. One of the nice things that happened recently is that Andrew Reynolds [Professor of Medieval Archaeology at the IoA] produced a photocopy from a local journal of 1869 that concerned William Stukeley, the antiquarian and father of druidry (he was the first self-proclaimed druid in Britain). It showed that back in the 1720s he had actually noted where the holes left by the big sarsen stones taken for Stonehenge still survived. That information has been lost for 150 years and Andrew just happened to turn up a photocopy. He was actually pointing me at something else in the paper, which was quite interesting, but then I saw this and thought 'oh my word...' That's given us something new to look for out of the old stuff, and it combines with a lost sketch by William Stukeley that was found ten years ago showing where some of the stones for Stonehenge appear to have been dragged and left; they're not there anymore, but we can use his sketch to locate the exact piece of ground. We're going to be digging there next year to see if we can find the exact location of those stones before they were broken up to put into people's houses. But in a way what's more exciting is what's happening in Wales because it's an absurd distance to bring stones: 140 miles as the crow flies...lunacy, and yet they did it.

\section{PIA: So actually when you talk about working on Stonehenge it involves a mas- sive network of other sites...}

MPP: I think that's it: it's about realising that the tentacles of Stonehenge reached very far indeed, and that's part of understanding what it's all about; it was a monument to involve everybody. We found one of the quarries last year, thanks to coordination with 
various geologists, and this year we actually identified the precise spot where one of the megaliths was taken out of the rock to go to Stonehenge. I just received an email today [12 November 2012] to say that we'll get the results of the dating in three weeks' time. These are the results of a ten-year test, because much will depend on whether we're right in terms of the date we've speculated that the stones were moved to Stonehenge. Another possibility, which we're looking into now, is that the reason they were all brought from Wales is that they were brought from another stone henge - that there was another stone circle in Wales that was dismantled and that is what the whole business was about: combining two important monuments into one. We think we've located that henge, so that's what we're going back to next summer and hoping to take UCL students with us for the first time. In a way it's the most exciting bit of the whole venture, and I wouldn't have thought that was possible when we started in 2003. I had no idea that it would lead from looking down by the side of the river near Stonehenge to heading off into these different areas. I think that we just now know so much more than we did a decade ago when we started. It's a cliché, but it really has been like a detective story.

\section{PIA: Do you think there's any sense in which the global profile of Stonehenge diverts attention away from other aspects of Prehistory?}

MPP: It's a gateway. It's one of the things along with aliens, lost arks, mummies and pyramids - that attracts the general public. Most people have heard of Stonehenge, and it can be very annoying, but we're very lucky that there are places like that which act as magnets for people who know nothing about archaeology. It's immediately recognisable, there's the mystery of: 'was it built by space aliens? Was it built by some higher civilisation? How could these barbarians have knocked up something like that?' etc etc. It's easy to say "bloody Stonehenge, it takes all the attention away from other things", but it's really important as a gateway for people to come to understand a bit more about what archaeology's really about.

\section{PIA: Stonehenge has obviously been cen- tral to your career...}

MPP: I didn't want it to be! I thought I'd got as far away from it as possible by starting work in Madagascar in the early 90s. That, by extraordinary fortune, was what brought me to it. I had no inkling whatsoever to go anywhere near the place in intellectual terms. I think part of it is that it has been very jealously guarded by anybody who comes into contact with it, whether they be druids, academics, government officials, politicians...you name it. As one of my geologist colleagues put it: "beware of the power of the ring"! It turns people into very territorial creatures about access and rights and all the rest of it. I wanted to keep a very wide berth around it; I'm happy to carry the ring, but I'm not going to wear it!

\section{PIA: So how did you come to be involved with Stonehenge?}

MPP: It was just the fortune of meeting up with Ramilisonina, the luckiest person we have ever met. We started work with him 1991 in the middle of a general strike in Madagascar; the entire country was closed down. There was no diesel or other fuel, there were no government agencies open to stamp our papers and do all that sort of thing, and somehow he took us from one end of Madagascar to the other and we had a really successful field season. He was one of those people who is immensely lucky and I can't explain it. Actually, I'm sure that it's not really to do with luck... it's his extraordinary ability to turn around even the most difficult people in the most difficult of situations. We had the opportunity in 1998 to invite him to Britain for a television documentary we were making about Stonehenge, and it was solely because someone had heard that I was working in Madagascar and they 
knew that Madagascar was where people put up standing stones and megaliths; I had said "this is the person you need, because his family do this sort of thing for real". We went to Avebury first of all, as darkness was falling, and he looked at me and said "what do you mean you don't know what they're for? Have you learned nothing? We've been working in Madagascar for the best part of ten years together and you seem to have failed to understand what standing stones are all about." So we wrote a paper. And it was one of those papers where you get a sort of burning thing inside you that you've just got to get out. If all of your research comes out as something that is burning a hole in you, that's the best way to do it... Otherwise I can't understand how anyone can have the stomach for research; it's got to be a passion, it's got to be an obsession, it's got to just flow out of you like energy in a sense; the worst thing is doing something you don't have that feeling about - it's not going to work. So we pulled this thing out in three days, we just sat in my bedroom and wrote, and when it was published it provoked the most extraordinary set of reactions from professional colleagues. Some said it was the best thing they'd ever read, others said it was the worst, and you know that that's a good thing.

\section{PIA: Did those reactions polarise along old processual vs post-processual lines?}

MPP: No, not at all. It was too post-processual for some, not post-processual enough for others, so we got into various debates and arguments and I thought: 'this is pointless because we're going to go round and round debating various theories without actually increasing our database'. I realised later on how important it was that we started looking and started digging because quite a lot of the 'facts' that were considered totally immutable turned out not to be - they were mistakes. If we hadn't done it we'd still be working with the same so-called 'facts', going round and round in theoretical debate. That said, after he and I wrote the paper, we really sat back and I thought 'someone else is going to want to do the fieldwork now; because we've set up the hypothesis, someone else can go and find it out - I'm not a Stonehenge person, I'm not part of that group who jealously guards the place intellectually'...and four years went by and nothing was happening. That was 2002, and the trouble was that it was burning a hole in me. I had to know. I didn't mind if other people found it out, but I had to know. Were we completely wrong that Durrington Walls was going to be a big place for the living (full of settlements as it turned out)? Come 2002 I decided that we were going to have to do this ourselves, so that's when I contacted Colin Richards who said "yes, I'll do it, but we'll need a big team".

\section{PIA: How many are there?}

MPP: I guess there are about thirty people who are working on it in different capacities and different levels of permanence.

\section{PIA: Will you ever be glad to be rid of Stonehenge?}

MPP: Well ... the monographs are not the end of it. Those are just writing-up. I think at the moment we're on our next adventure which is the sources of the stones and I think that is going to tell us a huge amount more about what Stonehenge is all about. Where it will go from there I don't know. Maybe that will be the end of the line, the end of the trail. But I could never have guessed that when we started all that time ago that it would run so far and in such diverse directions. If we're lucky, it will continue and open up new avenues for investigation that we simply haven't thought about before. I think the other thing is that I'm more and more conscious that there is a lot more to be done than just Stonehenge, so at the moment I'm looking at a project which will be Europe-wide looking at Bell Beakers, and particularly the domestic and settlement domain. Part of this would bring us back to a project that I've been running much longer than Stonehenge in the Outer Hebrides where we've been looking at 
long-term settlement and dwelling from prehistory to the historical period and one missing gap is the Early Bronze Age Bell Beaker stage. We know where the houses are, we've just never had the opportunity to investigate them. That's an important thing to keep on. We've spent twenty years working with one very small community on quite a small island and it's somewhere that I will always go back to. We've invested a lot of our lives and the people who live there now see us as part of the furniture as well, so we have a link there that I think will continue for a long time yet.

PIA: Do you think there are any limits to the meaningful interpretation of the mental world of pre-literate societies? Is there an event horizon for cognitive archaeology?

MPP: It's incredibly difficult. What we do is the most important of the humanities disciplines and it's the most difficult discipline on the planet because our subjects are all dead and most of what they've left behind has been severely knackered in one form or another and gone through all sorts of cultural and non-cultural transformations. We're the crime inspectors who have turned up long after the trail has gone cold. I think that to get any kind of inferences of who they are, why they're doing what they're doing, is very hard. And I think the only interesting question is 'why?' But it's the hardest one to ever answer. We can do quite a lot of 'how', 'when', 'where' and sometimes 'who', but the question 'why'... that has to take us into realms of meaning.

PIA: One of the reasons for asking the question is that I recently read an afterword by Ronald Hutton appended to a book on the subject of Anglo-Saxon paganism (Hutton 2010) in which he likened attempts to understand the mental architecture of past peoples to the study of a sealed tin: we might be able to read the label with increasing subtlety, but we can't get any closer to finding out what's inside. Would you agree with him?
MPP: No of course not. Ron's a historian; he deals with the written word. He's an immensely clever guy and I think his work is fantastic, but we're experts in material culture and it's a very different medium. Yes it's intractable, but there are questions we can ask - and if we're asking the right questions then I think we can answer quite a lot of these notions that seem so difficult. When I think of what we've done with Stonehenge, that really does show that we can move things a lot further along and, ok, it's never going to become non-mysterious, but I think we can actually give very plausible and consistent explanations of what was going on and what made them [the megalith builders] want to do it. And you can also see that much bigger picture; in archaeology context is everything. The problem with people trying to investigate Stonehenge is that they've never looked outside of it. It's a thing in itself which is immediately divorced from not just its landscape, but its entire setting within Britain, within Europe. You've got to see it in terms of those big processes, that big picture, as much as the nitty-gritty issues of sight lines and all the rest of it within the thing itself. A lot of the clever stuff that you can get out of philosophers of science puts it very nicely. Alison Wylie, for example (she was part of our big post-processual group in the late "70s and early '80s, now a hot-shot professor of the philosophy of science in the US [the University of Washington, Seattle), talks about how you triangulate the different strands of evidence (Wylie 2002). So we're not stuck on the wrong side of a concrete wall, we have ways round and over.

PIA: Do you see an end to very fixed disciplinary boundaries with the splintering of archaeology into lots of very different schools of thought and practice?

MPP: A lot of it was predicted by David Clark in his Age of Innocence paper (Clarke 1973); he realised the splintering was going to happen. Since my postgraduate days I've always seen us as studying material culture past and 
present, and our colleagues in anthropology - Chris Tilley, Danny Miller - would very much say that's what they do as well. I was surprised to discover that not all archaeologists embrace that idea - that we study material culture, wherever, whenever - but for me that's one of the underlying things...it's not about the 'past-ness' itself.

There's also a second key theme, which is that we're perhaps in a unique position, because of our long-term back projection, to be able to say: 'this is where we've got to, this is the rate, the processes, the changes, we can actually talk about what's happening to our society in a very long-term sense. And it's interesting that a few of the big thinkers have said 'oh yes, that's interesting, that's actually quite important'. Eric Hobsbawm, who died just the other day, had just been starting to write about how we should be looking at the last 15,000 years, not just the last 500 or 1000 or 2000. Jared Diamond, a biologist whose favourite subject is birds of paradise from New Guinea, has written a series of prize-winning books - he's a Pulitzer prize winner - and in one of them he says "thank heaven for archaeologists and television" because we are just racing towards disaster for the human species, we are making our lives and our world for ourselves tougher and tougher (Diamond 2005). He's just one of a few big thinkers and I think even if we ourselves as archaeologists can't write that picture we have to at least provide the information for that big picture. You can always find fault with someone like Jared's writing because in a sense he is coming at it like a journalist - it's not his field of expertise. He's an extraordinary guy, he's like a human encyclopaedia, but even so, you can always say, as a specialist: 'that's not quite right what he says about the ancient Maya and the demise of their agricultural system'. There's a lot of nit-picking by colleagues. But I think it's still important that he's trying to bring it all into a sensible, bite-sized package for people to read and think 'blimey, we must change what we're doing', because we can't go on like this in any sustainable form for more than a millennium or two, if that. Just getting the notion of long-term thinking is important - we're lucky if someone thinks ten years ahead in this world.

\section{PIA: What do you think the challenges are for archaeology going into the future?}

MPP: No one else is placed to provide the big picture for the development and evolution of the human species and its transformations through material culture and of the environment. It's a really important thing we have to do. And of course with that goes the whole business of communicating to a wider world. I think that communication is an issue - we're not always the best placed people to do it because we're not, by and large, trained as actors and entertainers and all the rest of it; we have to put our trust in others who produce and present and that's where things can go horribly wrong. Also we have to ask to what extent is what we're telling the public merely escapism, or are we trying to say this is really something interesting and you should be thinking about these issues. I've sometimes wondered whether a lot of our TV archaeology is just saying to people 'here's a bit of infotainment for you'... they're going to find a few sherds of poetry but they're not really going to tell you about how the world has come to be the way it is, and what the implications of that might be for where it's going, and maybe we need to focus a bit more on that these days.

The other difficulty is that I wonder if more and more regions of the planet where archaeologists have been happily gathering data are becoming less available to us. In part it's the cold hand of the post-imperial legacy - the lands of the Middle East and the Near East are increasingly off-limits, and I'm not sure that there are others that are opening up to make up for that. If I were an archaeologist again I would want to be working in South-Eastern Turkey. I'd like to be working along with old Schmidt [Klaus Schmidt of the German Archaeological Institute] at Göbekli Tepe... 
It's fantastic, mind-bogglingly amazing... I'm afraid it makes Çatalhöyük look rather boring! It's not the only one of it's kind, it's probably the biggest and most impressive. I would give up having anything to do with Stonehenge like a shot to go and work somewhere like that. I think it has stunned us all that you have this kind of labour organisation - this kind of megalith construction with elaborate carving and so on - at that very, very early point in the Holocene right at the end of the Younger Dryas. It's just stunning, as if it's come out of nowhere. Its roots must lie somewhere in the Epipaleolithic and, of course, the next question is: "what is happening in the immediately preceding period to trigger this kind of event?' It is the first of the really extraordinary transformations that happens in the Holocene as we're building up to the big aggregations of people, those events that changed the world. And it's that area, basically from Turkey southwards into Iraq, which seems to be so crucial for the most important transition I think that humans have been through. It's where the whole gearing-up ultimately to urbanism and the world as we know it began... That's the most important change; from being freewheeling hunter-gatherers to being a very different kind of animal to the one that we were before.

\section{PIA: You have a burning passion for pre- history...is there any other period that interests you as much?}

I think the thing is that as an archaeologist I love it all. But I think the reason that prehistory in particular appeals is because it is so much more difficult. We don't know what these things or places were called even. When someone says we're going to dig up a medieval church, you know they're going to dig up a medieval church...I think text-aided archaeology sometimes doesn't quite have the challenges, it's not as difficult. It's not easy by any means, and I think the real role of text-aided archaeology is to undermine those texts and say 'actually, you thought you knew what was going on, because it's all written down...well you're wrong!'; it's not just the voices of those who never contributed to the texts, it's also dealing with how people perceived their society as opposed to what was actually going on. But what's important about prehistory is that you're starting with nothing; you're starting with silence. The other aspect is actually the nature of the evidence itself. I trained in the Roman period - I was going to be a Romanist - and then after a while I discovered that actually finding walls of villas and the like wasn't actually that taxing - you find a wall and it just goes straight until it turns - whereas prehistoric houses are extremely difficult because you've got to dig so much more carefully, so much more thoughtfully. That for me has been the joy of it; to be able to say 'look! We haven't seen one of these before.' And you may not know what they called it, but you've found one... even if it's just a boring little house.

\section{References}

Clarke, D 1973 Archaeology: the loss of innocence, Antiquity 47, No. 185 (March), 6-18.

Diamond, J 2005 Collapse: How Societies Choose to Fail or Succeed, Viking.

Hutton, R 2010 Afterword: Caveats and Futures, in M. Carver, A. Sanmark and S. Semple (eds.), Signals of Belief in Early England: Anglo-Saxon Paganism Revisited, Oxford, Oakville; Oxbow Books.

Wylie, A 2002 Thinking from Things: Essays in the Philosophy of Archaeology. Berkeley, California: University of California Press. 